\title{
Local Galvanic Distortions in the Central Part of North-Eastern Japan (Part 1)
}

\author{
Noriaki KaWAKamI ${ }^{1}$, Yukio Fujinawa ${ }^{2}$, Theodore H. ASCH ${ }^{1}$, and Shinji TAKASUGI ${ }^{1}$ \\ ${ }^{1}$ Geothermal Energy Research and Development Co., Ltd., 11-7, Kabuto-cho, Nihonbashi, Chuo-ku, Tokyo 103, Japan \\ ${ }^{2}$ National Research Institute for Earth Science and Disaster Prevention, Tennohdai 3-1, Tsukuba 305, Japan
}

(Received November 29, 1996; Revised September 30, 1997; Accepted September 30, 1997)

\begin{abstract}
Wide-band $(20,000 \mathrm{~Hz}$ to $0.002 \mathrm{~Hz})$ magnetotelluric (MT) observations have been conducted since 1990 in the central part of the Tohoku district in the northeastern part of Japan to investigate the deep electrical resistivity structure. MT data were obtained on three east-west-trending MT transects about 140 $\mathrm{km}$ long and separated by about $20 \mathrm{~km}$. In this paper we investigate three-dimensional gal vanic distortions on the three transects using the Groom-Bailey tensor decomposition technique. We have focused on the regional strike direction and are not considering static shifts in the data. The decomposition method worked well at most sites but failed at some sites suggesting considerable regional three-dimensionality there. We found that the north-northwest to south-southeast direction is the predominant regional strike. This direction coincides with the regional geological strike being nearly perpendicular to the subduction direction of the Pacific plate. The induction vectors are generally in agreement with the regional strike direction deduced by the decomposition method on the southernmost line, but they deviate systematically on northernmost and middle lines suggesting conductivity contrasts in these areas.
\end{abstract}

\section{Introduction}

The Tohoku district of northeastern Japan is situated on a subduction zone where the Pacific plate (oceanic material) is subducting beneath the North American plate (continental material) (Fig. 1). Many geological and geophysical studies have been conducted in this district (see Fujinawa et al., 1997, hereafter cited as F).

Ogawa (1987a) carried out two-dimensional resistivity modeling based on a regional broadband magnetotelluric survey following earlier studies by Honkura (1974), Ogawa et al. (1986) and Utada (1987) which used a more limited frequency band. Ogawa (1987a) concluded that the lower crust below the island arc is conductive $(10 \sim 300 \mathrm{ohm} \cdot \mathrm{m})$ and Ogawa (1987b) attempted a qualitative three-dimensional interpretation from mapping induction vectors and discussed the three-dimensionality of that district. In the southern part of the Tohoku district, Ogawa (1992) conducted a MT transect to investigate deep crustal structures. However, the regional resistivity structure in the central part of the Tohoku district between the two regions surveyed by Ogawa (1987a, 1992) has not been studied in detail.

NIEDO and GERD have been conducting broadband MT surveys since 1990 in the central part of Tohoku district to study the geoelectrical structure in this subduction region (square area shown by dotted lines in Fig. 1). We have conducted three surveys consisting of a total of 70 sites over the last six years in order to clarify and detail the resistivity structure in this area. Based on geological information, the regional strike is assumed to be approximately north-south. Therefore the traverse orientations have also been set to trend nearly east-west. From the analysis of the impedance tensor data, it was found that there were considerable scatter in the impedance strikes and some inconsistencies with the tipper strikes at many sites. The tipper magnitude and skew suggest that the region can be generally treated as 2-D. But because the tipper magnitude and skew are locally quite large, local 3-D structure can not be neglected in the more detailed modeling. It has been assumed that localized surface heterogeneities are contributing to some of the distortions observed in the impedance tensors other than genuine 3-D heterogeneities.

In this paper, we present the results of the simple and practical decomposition method of Groom and 


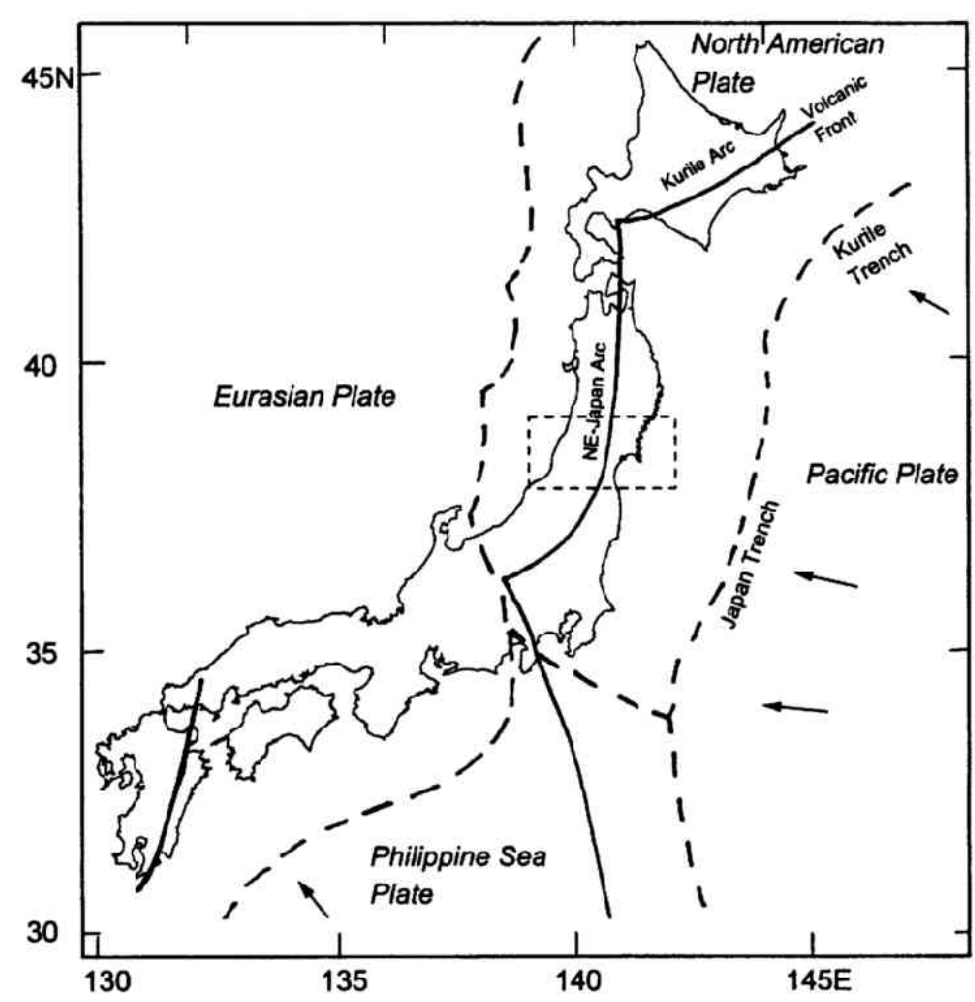

Fig. 1. Distribution of the tectonic divisions of Japan (revised from figure 3-1 of Ogawa, 1992). The Pacific plate (oceanic material) is subducting beneath the North American plate (continental material). The studied area is located in the central part of the Tohoku district which is shown by rectangle shown by dotted lines.

Bailey (GBD) (Groom and Bailey, 1989, 1991; Groom et al., 1993) which treats the galvanic distortions due to local resistivity heterogeneities near the ground surface. Through these analyses we can learn the degree to which galvanic distortion effects due to surface heterogeneities distort the measured impedance tensors. During this process we are assuming a 2-D structure for the data obtained in the central part of Tohoku, Japan. Furthermore, we can also determine appropriate regional directions to apply while building 2-D resistivity models. Site gain factors, one of the GBD distortion parameters, are not dealt with here. Static shift corrections are made using TEM data (Fujinawa et al., 1997) to complete the evaluation of galvanic distortion effects.

\section{Geological Setting}

The central part of Tohoku district, from topographical and geological points of view, is roughly divided into five, generally north-south trending, zones (Fig. 2) resulting from extensive tectonic motion by the Pacific plate in and around the district. There are three high altitude zones, the Dewa Hill, the Oou Mountain Range, and the Southern Kitakami Mountain zone (Oide et al., 1989). The Dewa Hill is the westernmost highland zone and consists of Tertiary sediments and volcanics and the Asahi granite body. East of the Dewa Hill are the Yamagata and Shinjo basins. The second highland moving further eastwards is the Oou Mountain Range consisting mainly of Quaternary volcanics. East of the Oou Mountain Range is the Kitakami-kawa alluvial plain. The easternmost zone is the Southern Kitakami region and consists of pre-Tertiary sediments and granites.

More information about the geology and tectonics of the Tohoku district can be seen in F. In order 


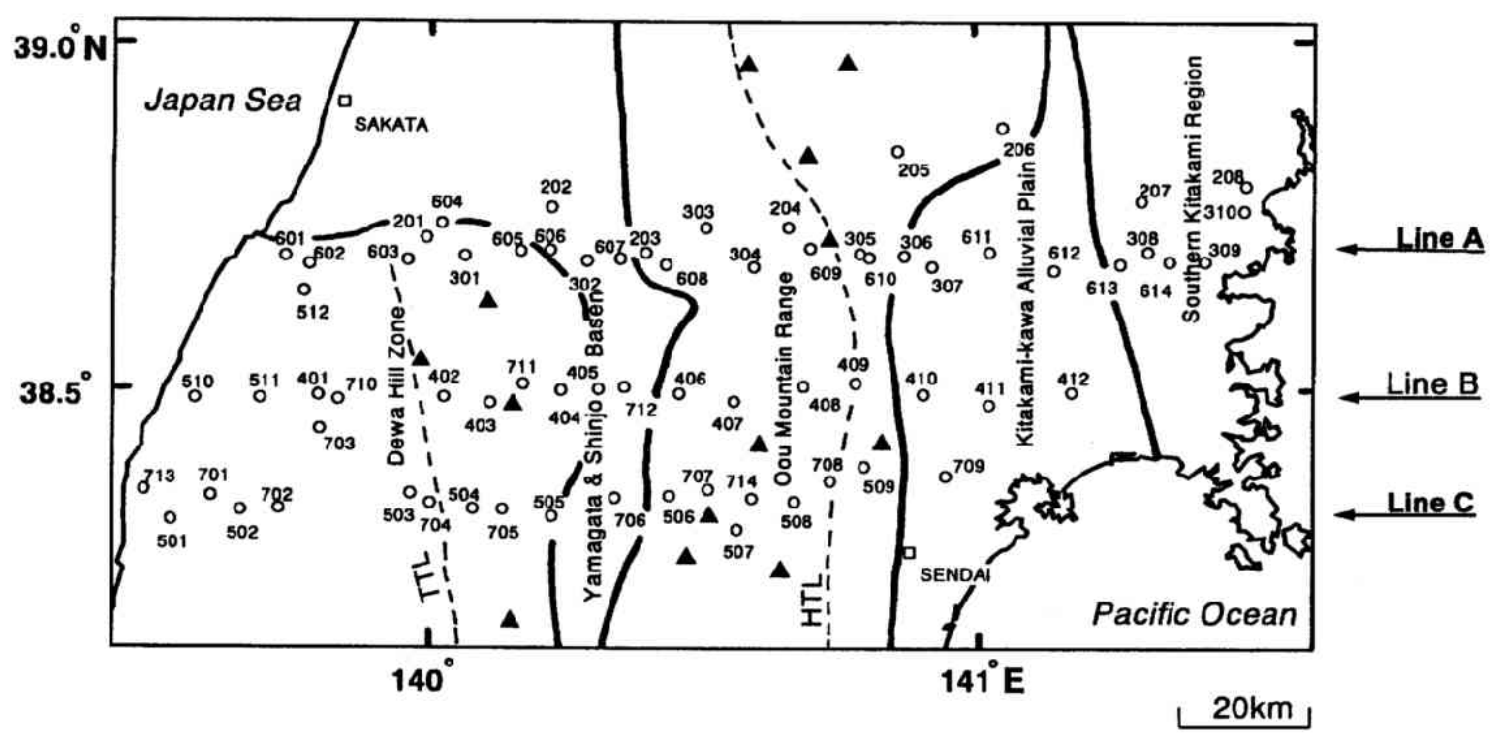

Fig. 2. Location of the MT measurement sites and geologic divisions (after Geological Survey of Japan (ed.), 1995). Triangles denote Quaternary volcanoes. TTL is the TANAKURA tectonic line and HTL is HATAGAWA tectonic line.

to investigate the geology and regional tectonics in more detail with reference to the seismic and volcanic activity we have been measuring more detailed resistivity profiles including taking into accounts various site effects such as coastal and surface heterogeneities.

\section{Results of the Groom-Bailey Decomposition Method}

Three transect surveys of MT have been conducted in the Tohoku district which runs approximately east-west (Fig. 2). The northernmost line (Line A) consists of 33 sites, the middle line (Line B) has 18 sites, and the southernmost line (Line C) consists of 19 sites. The frequency range of the MT measurements is from $20,000 \mathrm{~Hz}$ down to $0.002 \mathrm{~Hz}$. The principal direction calculated from the observed impedance tensor and the tipper strike from the magnetic transfer function did not produce consistent structural directions suggesting effects of surface heterogeneities and/or genuine three dimensional structures. We first evaluated the effects of subsurface heterogeneities.

The magnetic transfer function (tipper) is one source of information used to determine the regional strike. However, the Groom-Bailey decomposition method has also proved to be very useful in determining both the regional strike and undistorted impedances. We applied the Groom and Bailey decomposition (GBD) method to deduce the regional strike at the nineteen sites on Line $\mathrm{C}$ to check the performance of the method applied to data obtained in this district. Then the data on Lines A and B were analyzed. The reason why we selected Line $\mathrm{C}$ for this study is because the induction vectors at the sites on this line correlate well with the known regional structure of the Tohoku district. This indicates that a two dimensional structure is a good approximation in this region.

Since the Groom-Bailey decomposition method is based on the assumption that the model is regionally two-dimensional and locally inhomogeneous, deviation from this assumption inhibits the ability of the method to successfully resolve the undistorted impedance tensor. As a matter of fact, we had several sites that presented some difficulty to direct application of the GBD technique. The subduction system in the district is known to have undergone a substantial change in the Neogene such as a subduction direction change, displacement of the volcanic front, and regional depression and uplift (Kimura et al., 1991). Thus the whole of the Tohoku district can not be strictly assumed to be regionally two-dimensional. 
Application of the Groom-Bailey technique to the data on Line $\mathrm{C}$ produced results consistent with the geological setting at many of the nineteen sites. Since there are already many case histories illustrating that the Groom-Bailey decomposition method works well (e.g., Groom et al., 1993), we do not here describe those cases from Line $\mathrm{C}$ which provide fine results with an error of misfit for the two-dimensional parameterization being less than the acceptable level of 4.0. Rather in the following subsections, we show some typical cases in which the GBD could not be simply applied and how we then decided on the regional strike for these data.

\subsection{Marginal case}

Figure 3 presents the distortion parameters for Site 502 using the Groom-Bailey decomposition procedure. If we constrain the parameters as frequency independent, $\chi^{2}$ exceeded the tolerance level $\left(\chi^{2}\right.$ $<4)$ at higher frequencies $(>0.5 \mathrm{~Hz})$. Thus the regional structure is not simply two-dimensional around Site 502 suggesting the possibility of considerable three-dimensionality. Assuming the simple case that there are two layers with different regional strike directions we divided the frequency band into high $(>0.5$ $\mathrm{Hz})$ and low $(<0.5 \mathrm{~Hz})$ bands. The GBD was then, carried out separately for each band. The results are plotted in Fig. 4. Note that the residual error at the higher frequencies is now much lower than that in Fig. 3. The regional strike is $\mathrm{N} 18^{\circ} \mathrm{W}$ in the shallower depths and approximately $\mathrm{N} 2^{\circ} \mathrm{W}$ at greater depths.

Figure 5 illustrates a schematic model of the resistivity structure including surface inhomogeneities around Site 502 as obtained by the decomposition analysis. In the shallower depths, some surface

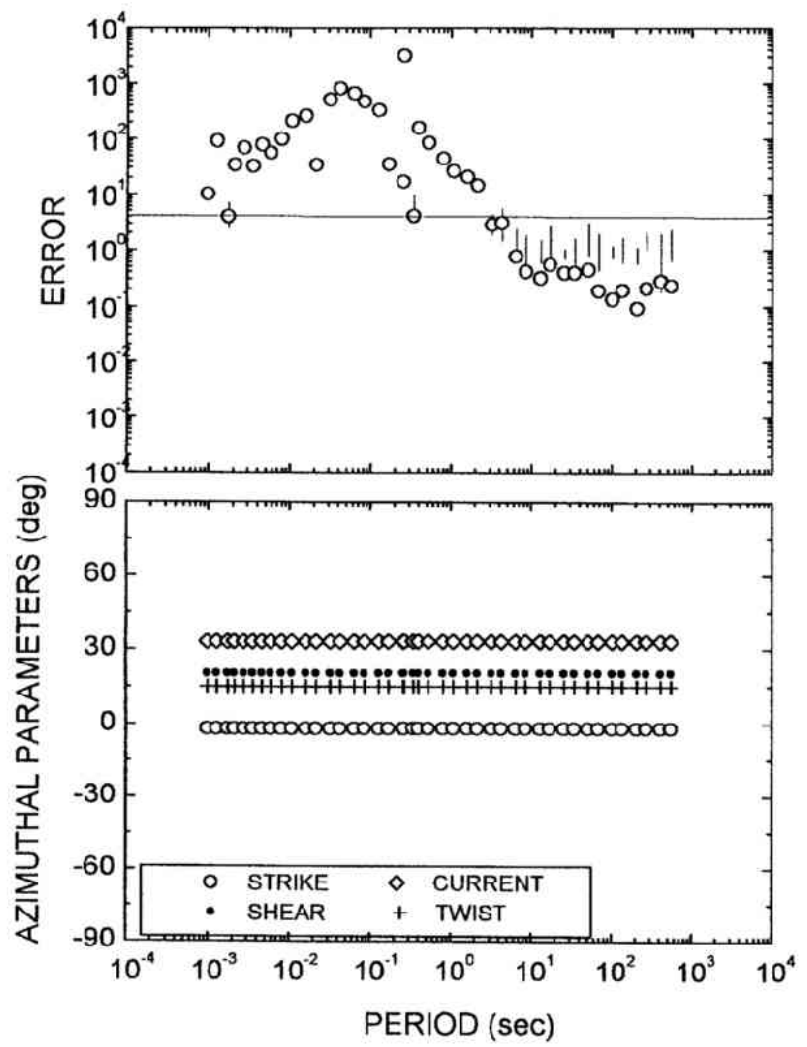

Fig. 3. The residual error and azimuthal parameters (regional strike, current channeling azimuth, shear and twist) for a threedimensional model parameterization (Groom and Bailey technique) for Site 502. All parameters held constant. The residual error at higher frequencies is very high. 


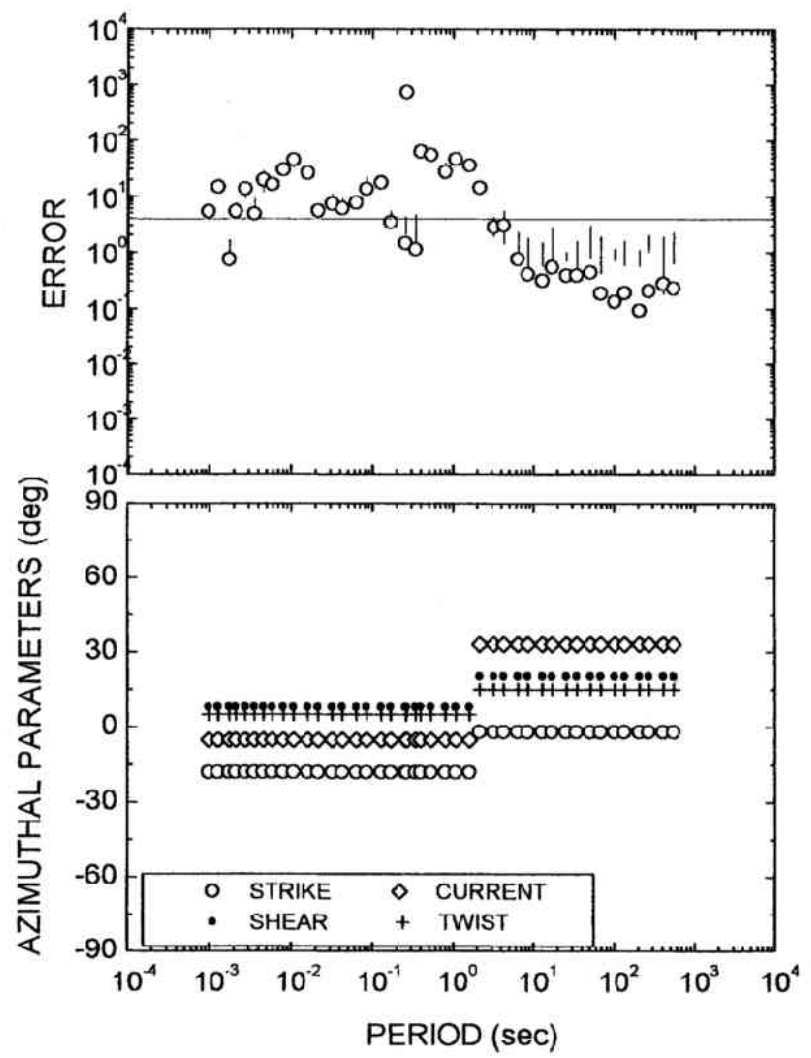

Fig. 4. The residual error, strike, twist and shear for Site 502 by the Groom and Bailey technique with separated frequency bands assumption. The residual error at the higher frequencies is much lower than that in Fig. 3.

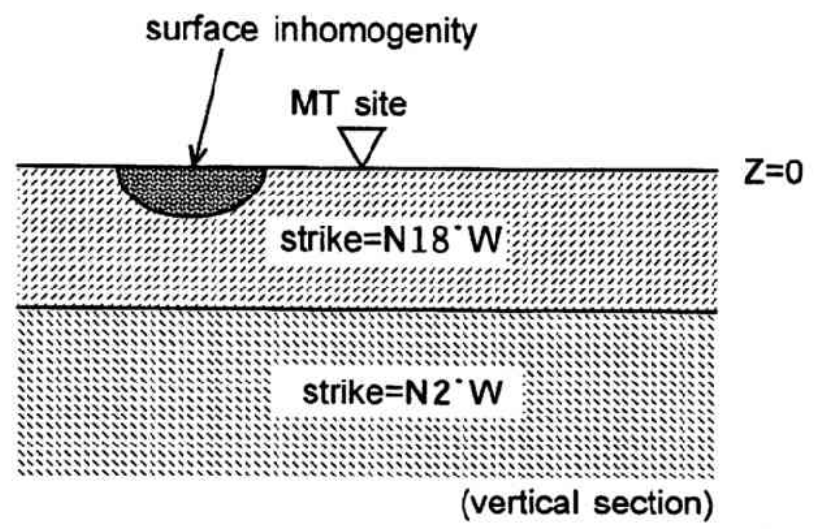

Fig. 5. The schematic resistivity model near Site 502 deduced from referring to the results of the decomposition analysis. The regional strike is $\mathrm{N} 18^{\circ} \mathrm{W}$ in the shallower depths and approximately $\mathrm{N} 2^{\circ} \mathrm{W}$ at greater depths with surface heterogeneities near the site. 

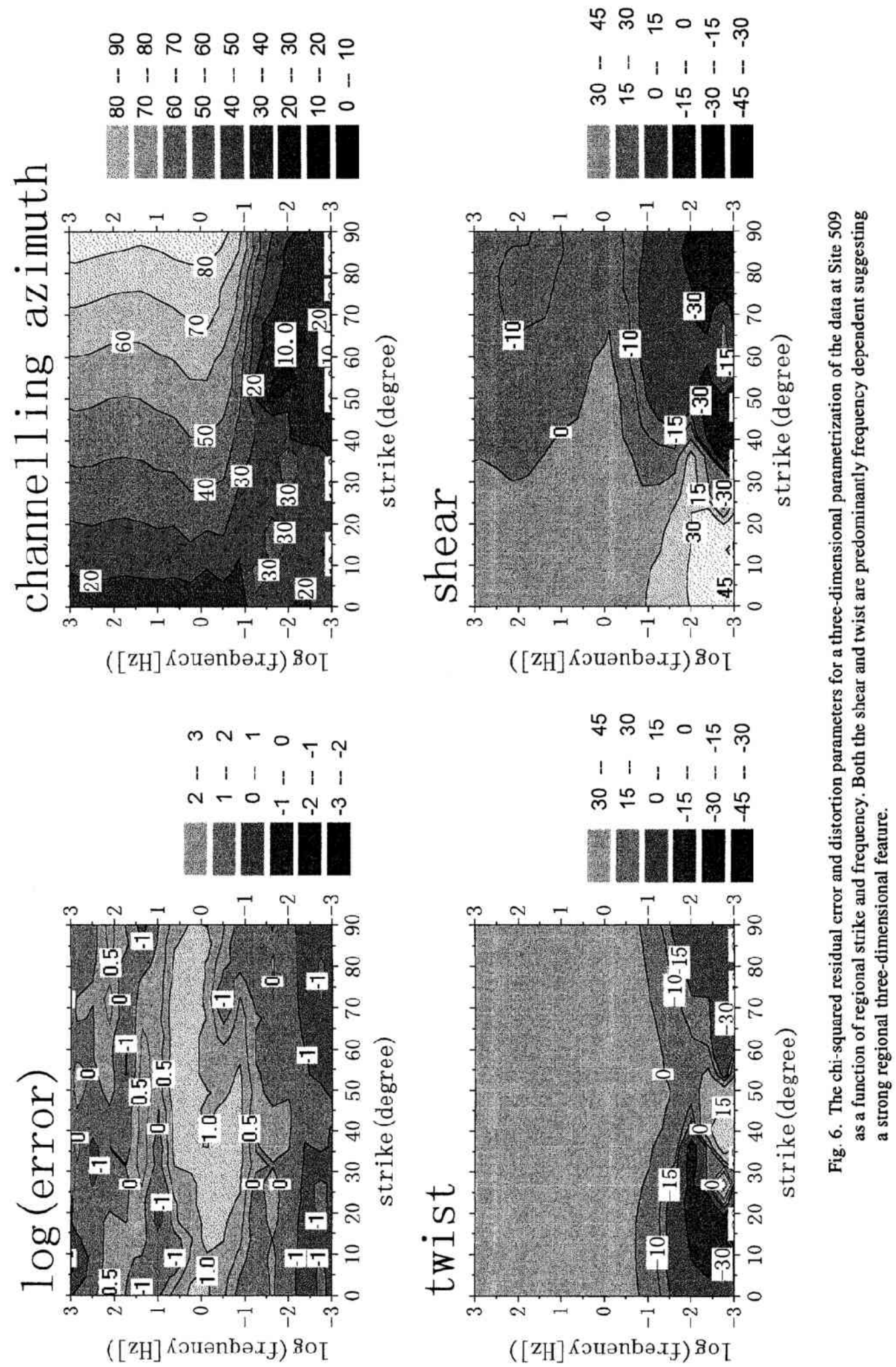
inhomogeneities cause the distortions in the impedance tensor, where the regional strike direction is $\mathrm{N} 18^{\circ} \mathrm{W}$. However this regional strike direction does not coincide with that determined at deeper depths $\left(\mathrm{N} 2^{\circ} \mathrm{W}\right)$. It must be noted that the meaning of the terms "local" and "regional" depends on the scale under consideration. At Site 502, the shallower structure is locally inhomogeneous relative to the regional structure at greater depths.

\subsection{Improper case}

Figure 6 shows plots of the distortion parameters (channeling azimuth, twist and shear) and residual error as a function of strike and frequency for Site 509. Both the shear and twist are predominantly frequency dependent at a period above some tens of seconds. Therefore a plausible regional strike angle can hardly be determined even by dividing the frequency region into some bands as tried in the previous case. It might be caused by a more complex three-dimensional heterogeneity which can not be treated in the realm of the galvanic distortions as is assumed in the GBD technique. We discuss the possible cause

Table 1. The regional strikes, local current directions, shears and twists determined by the Groom-Bailey decomposition method for all the sites on the three transects.

\begin{tabular}{|c|c|c|c|c|c|c|c|c|c|}
\hline Site & $\begin{array}{l}\text { Regional } \\
\text { strike }\end{array}$ & $\begin{array}{c}\text { Shear } \\
\text { (degree) }\end{array}$ & $\begin{array}{c}\text { twist } \\
\text { (degree) }\end{array}$ & $\begin{array}{c}\text { Local } \\
\text { current }\end{array}$ & Site & $\begin{array}{c}\text { Regional } \\
\text { strike }\end{array}$ & $\begin{array}{c}\text { Shear } \\
\text { (degree) }\end{array}$ & $\begin{array}{c}\text { twist } \\
\text { (degree) }\end{array}$ & $\begin{array}{c}\text { Local } \\
\text { current }\end{array}$ \\
\hline 201 & $\mathrm{~N} 46^{\circ} \mathrm{W}$ & 0 & 0 & $\mathrm{~N} 46^{\circ} \mathrm{W}$ & 506 & $\mathrm{~N} 15^{\circ} \mathrm{W}$ & 20 & 10 & $\mathrm{~N} 15^{\circ} \mathrm{E}$ \\
\hline 202 & $\mathrm{~N} 0^{\circ}$ & 25 & 0 & $\mathrm{~N} 25^{\circ} \mathrm{E}$ & 507 & $\mathrm{NO}^{\circ}$ & 22 & 10 & $\mathrm{~N} 32^{\circ} \mathrm{E}$ \\
\hline 203 & $\mathrm{~N} 0^{\circ}$ & 30 & -5 & $\mathrm{~N} 25^{\circ} \mathrm{E}$ & 508 & $\mathrm{~N} 15^{\circ} \mathrm{E}$ & 6 & 0 & $\mathrm{~N} 21^{\circ} \mathrm{E}$ \\
\hline 204 & $\mathrm{~N} 30^{\circ} \mathrm{W}$ & -25 & -15 & $\mathrm{~N} 70^{\circ} \mathrm{W}$ & 509 & $\mathrm{~N} 20^{\circ} \mathrm{W}$ & 30 & -20 & $\mathrm{~N} 10^{\circ} \mathrm{W}$ \\
\hline 205 & $\mathrm{~N} 18^{\circ} \mathrm{W}$ & 0 & 0 & $\mathrm{~N} 18^{\circ} \mathrm{W}$ & 510 & $\mathrm{~N} 30^{\circ} \mathrm{W}$ & -30 & 8 & $\mathrm{~N} 52^{\circ} \mathrm{W}$ \\
\hline 206 & $\mathrm{~N} 0^{\circ}$ & 23 & 0 & $\mathrm{~N} 23^{\circ} \mathrm{E}$ & 511 & $\mathrm{~N} 5^{\circ} \mathrm{W}$ & 30 & 3 & $\mathrm{~N} 28^{\circ} \mathrm{E}$ \\
\hline 207 & $\mathrm{~N} 45^{\circ} \mathrm{E}$ & 25 & 0 & $\mathrm{~N} 70^{\circ} \mathrm{E}$ & 512 & $\mathrm{~N} 25^{\circ} \mathrm{W}$ & 8 & 10 & $\mathrm{~N} 7^{\circ} \mathrm{W}$ \\
\hline 208 & $\mathrm{~N} 5^{\circ} \mathrm{W}$ & 0 & 0 & $\mathrm{~N} 5^{\circ} \mathrm{W}$ & 601 & $\mathrm{~N} 0^{\circ}$ & 13 & -4 & ${ }^{N} 9^{\circ} \mathrm{E}$ \\
\hline 301 & $\mathrm{~N} 26^{\circ} \mathrm{W}$ & -25 & 5 & $\mathrm{~N} 46^{\circ} \mathrm{W}$ & 602 & $\mathrm{NO}^{\circ}$ & 13 & -12 & $\mathrm{~N} 1^{\circ} \mathrm{E}$ \\
\hline 302 & $\mathrm{~N} 0^{\circ}$ & 30 & 0 & $\mathrm{~N} 30^{\circ} \mathrm{E}$ & 603 & $\mathrm{~N} 40^{\circ} \mathrm{W}$ & 0 & -15 & $\mathrm{~N} 55^{\circ} \mathrm{W}$ \\
\hline 303 & No ${ }^{\circ}$ & 18 & 0 & $\mathrm{~N} 18^{\circ} \mathrm{E}$ & 604 & $\mathrm{~N} 0^{\circ}$ & 40 & 0 & $\mathrm{~N} 40^{\circ} \mathrm{E}$ \\
\hline 304 & $\mathrm{~N} 0^{\circ}$ & 10 & 0 & $\mathrm{~N} 10^{\circ} \mathrm{E}$ & 605 & $\mathrm{NO}^{\circ}$ & 35 & 0 & $\mathrm{~N} 35^{\circ} \mathrm{E}$ \\
\hline 305 & $\mathrm{~N} 30^{\circ} \mathrm{W}$ & 0 & 0 & $\mathrm{~N} 30^{\circ} \mathrm{W}$ & 606 & $\mathrm{NO}^{\circ}$ & 6 & 0 & N6 ${ }^{\circ} \mathrm{E}$ \\
\hline 306 & $\mathrm{~N} 20^{\circ} \mathrm{W}$ & 0 & 0 & $\mathrm{~N} 20^{\circ} \mathrm{W}$ & 607 & $\mathrm{NO}^{\circ}$ & 10 & -5 & $\mathrm{~N} 5^{\circ} \mathrm{E}$ \\
\hline 307 & $\mathrm{~N} 47^{\circ} \mathrm{W}$ & 0 & 0 & $\mathrm{~N} 47^{\circ} \mathrm{W}$ & 608 & $\mathrm{~N} 0^{\circ}$ & 30 & 0 & $\mathrm{~N} 30^{\circ} \mathrm{E}$ \\
\hline 308 & $\mathrm{~N} 26^{\circ} \mathrm{W}$ & 0 & 0 & $\mathrm{~N} 26^{\circ} \mathrm{W}$ & 609 & No ${ }^{\circ}$ & 0 & 0 & No ${ }^{\circ}$ \\
\hline 309 & No ${ }^{\circ}$ & 8 & 0 & $\mathrm{~N} 8^{\circ} \mathrm{E}$ & 610 & $\mathrm{~N} 40^{\circ} \mathrm{W}$ & 0 & 0 & $\mathrm{~N} 40^{\circ} \mathrm{W}$ \\
\hline 310 & $\mathrm{~N} 0^{\circ}$ & 0 & 0 & $\mathrm{~N} 0^{\circ}$ & 611 & $\mathrm{~N} 0^{\circ}$ & 0 & 0 & $\mathrm{~N} 0^{\circ}$ \\
\hline 401 & $\mathrm{~N} 45^{\circ} \mathrm{W}$ & 10 & 2 & $\mathrm{~N} 33^{\circ} \mathrm{W}$ & 612 & $\mathrm{NO}^{\circ}$ & 12 & 0 & $\mathrm{~N} 12^{\circ} \mathrm{E}$ \\
\hline 402 & $\mathrm{~N} 5^{\circ} \mathrm{E}$ & -1 & 1 & $\mathrm{~N} 5^{\circ} \mathrm{E}$ & 613 & $\mathrm{~N} 44^{\circ} \mathrm{E}$ & 38 & 0 & $\mathrm{~N} 82^{\circ} \mathrm{E}$ \\
\hline 403 & $\mathrm{~N} 5^{\circ} \mathrm{E}$ & -2 & 1 & $\mathrm{~N} 4^{\circ} \mathrm{E}$ & 614 & $\mathrm{~N} 26^{\circ} \mathrm{W}$ & 0 & 0 & $\mathrm{~N} 26^{\circ} \mathrm{W}$ \\
\hline 404 & $\mathrm{~N} 50^{\circ} \mathrm{W}$ & 30 & 1 & $\mathrm{~N} 19^{\circ} \mathrm{W}$ & 701 & $\mathrm{~N} 15^{\circ} \mathrm{W}$ & 30 & 18 & $\mathrm{~N} 33^{\circ} \mathrm{E}$ \\
\hline 405 & $\mathrm{~N} 45^{\circ} \mathrm{W}$ & 10 & 1 & $\mathrm{~N} 34^{\circ} \mathrm{W}$ & 702 & $\mathrm{~N} 5^{\circ} \mathrm{E}$ & 27 & 6 & $\mathrm{~N} 38^{\circ} \mathrm{E}$ \\
\hline 406 & $\mathrm{~N} 17^{\circ} \mathrm{W}$ & 3 & 0 & $\mathrm{~N} 14^{\circ} \mathrm{W}$ & 703 & $\mathrm{~N} 36^{\circ} \mathrm{W}$ & 10 & 0 & $\mathrm{~N} 26^{\circ} \mathrm{W}$ \\
\hline 407 & $\mathrm{~N} 25^{\circ} \mathrm{W}$ & -25 & -10 & $\mathrm{~N} 60^{\circ} \mathrm{W}$ & 704 & $\mathrm{~N} 30^{\circ} \mathrm{W}$ & 30 & 20 & $\mathrm{~N} 20^{\circ} \mathrm{E}$ \\
\hline 408 & $\mathrm{~N} 2 \mathrm{~W}$ & 8 & 5 & $\mathrm{~N} 11^{\circ} \mathrm{E}$ & 705 & $\mathrm{~N} 5^{\circ} \mathrm{E}$ & 0 & 1 & $\mathrm{~N} 6^{\circ} \mathrm{E}$ \\
\hline 409 & $\mathrm{~N} 0^{\circ}$ & 5 & 2 & $\mathrm{~N} 7^{\circ} \mathrm{E}$ & 706 & $\mathrm{~N} 45^{\circ} \mathrm{W}$ & 15 & 2 & $\mathrm{~N} 28^{\circ} \mathrm{W}$ \\
\hline 410 & $\mathrm{~N} 10^{\circ} \mathrm{W}$ & 5 & 2 & $\mathrm{~N} 3^{\circ} \mathrm{W}$ & 707 & $\mathrm{~N} 15^{\circ} \mathrm{W}$ & 7 & 5 & $\mathrm{~N} 3^{\circ} \mathrm{W}$ \\
\hline 411 & $\mathrm{~N} 20^{\circ} \mathrm{W}$ & 5 & 3 & $\mathrm{~N} 12^{\circ} \mathrm{W}$ & 708 & $\mathrm{~N} 18^{\circ} \mathrm{W}$ & 30 & -5 & $\mathrm{~N}^{\circ} \mathrm{E}$ \\
\hline 412 & $\mathrm{~N} 32^{\circ} \mathrm{W}$ & 3 & 0 & $\mathrm{~N} 29^{\circ} \mathrm{W}$ & 709 & $\mathrm{~N} 10^{\circ} \mathrm{W}$ & 30 & -8 & $\mathrm{~N} 12^{\circ} \mathrm{E}$ \\
\hline 501 & $\mathrm{~N} 10^{\circ} \mathrm{W}$ & 5 & 0 & $\mathrm{~N} 5^{\circ} \mathrm{W}$ & 710 & $\mathrm{~N} 30^{\circ} \mathrm{W}$ & -25 & -15 & $\mathrm{~N} 70^{\circ} \mathrm{W}$ \\
\hline 502 & $\mathrm{~N} 2^{\circ} \mathrm{W}$ & 20 & 15 & $\mathrm{~N} 33^{\circ} \mathrm{E}$ & 711 & $\mathrm{~N} 12^{\circ} \mathrm{E}$ & 30 & 25 & $\mathrm{~N} 67^{\circ} \mathbf{E}$ \\
\hline 503 & $N 15^{\circ} \mathrm{E}$ & 10 & 1 & $\mathrm{~N} 26^{\circ} \mathrm{E}$ & 712 & $\mathrm{~N} 15^{\circ} \mathrm{W}$ & 25 & -12 & $\mathrm{~N} 2{ }^{\circ} \mathrm{W}$ \\
\hline 504 & $\mathrm{~N} 10^{\circ} \mathrm{W}$ & 12 & -5 & $\mathrm{~N} 3^{\circ} \mathrm{W}$ & 713 & $\mathrm{~N} 15^{\circ} \mathrm{W}$ & 23 & 30 & $\mathrm{~N} 38^{\circ} \mathrm{E}$ \\
\hline 505 & $\mathrm{~N} 18^{\circ} \mathrm{W}$ & -2 & 2 & $\mathrm{~N} 18^{\circ} \mathrm{W}$ & 714 & $\mathrm{~N} 23^{\circ} \mathrm{W}$ & -35 & -20 & $\mathrm{~N} 12^{\circ} \mathrm{E}$ \\
\hline
\end{tabular}


in more detail in a later section.

In order to find the most plausible regional strike in the case of an assumed two-dimensional regime as was undertaken in $\mathrm{F}$, the regional strike angle for this site was inferred using the data in the period range below some tens of seconds in which the angle is frequency independent. In this case, the residual error is low around a strike angle of 40 degrees. The strike angle thus determined is based on information at a little bit shallower depth than at other sites.

\section{Regional Strike}

We determined the regional strike at the all sites on the three transects. At the good sites where twodimensionality can be assumed, we can use the results of the decomposition with some confidence. At sites classified as Marginal the strike angles were determined by choosing a strike corresponding to lowest frequency treated separately in the analysis. And, the strike at sites classified as Improper were determined rather subjectively taking into account the results of the decomposition analysis, especially the residual error plots.

In Table 1 are listed the final results of the Groom-Bailey decomposition method for all the sites. The 90 degree ambiguity in the regional strike was determined by referring to the nearby geology. From this table it is clear that three-dimensional local heterogeneities are not negligible for many sites as indicated by the finite values of the shear and twist parameters and the differences between the local current direction and the regional strike.

Figure 7 shows the determined regional strike directions which are indicated by bold lines passing through each site position. We can see that the structural direction in the central part of the Tohoku district is nearly north-northwest to south-southeast in spite of the appreciable deviations from the dominant direction at several sites. The regional direction is generally consistent with the direction of NE-Japan arc (Fig. 1) and the strike of the major geological divisions (Fig. 2) in comparison to much larger scatter and deviations of impedance strikes and tipper strikes. Here we can see another example of the excellent results produced by application of the Groom-Bailey decomposition method in the determination of the regional strike direction in the presence of the surface heterogeneities on the basis of data obtained in a very noisy

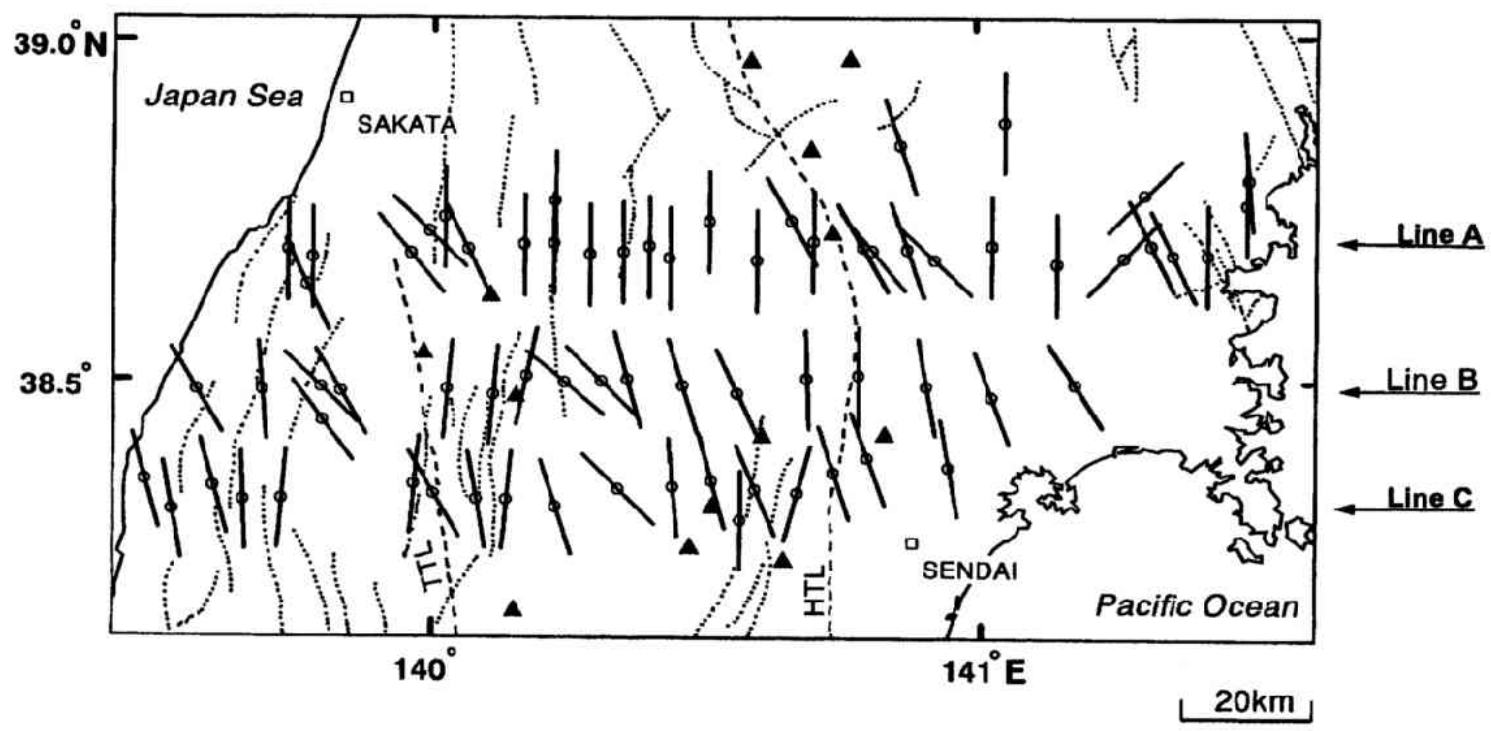

Fig. 7. The regional strike (bold solid line) resulting froma Groom-Bailey decomposition analysis of Lines A, B, C. Dashed lines are major tectonic lines and faults (after Geological Survey of Japan (ed.), 1995). 


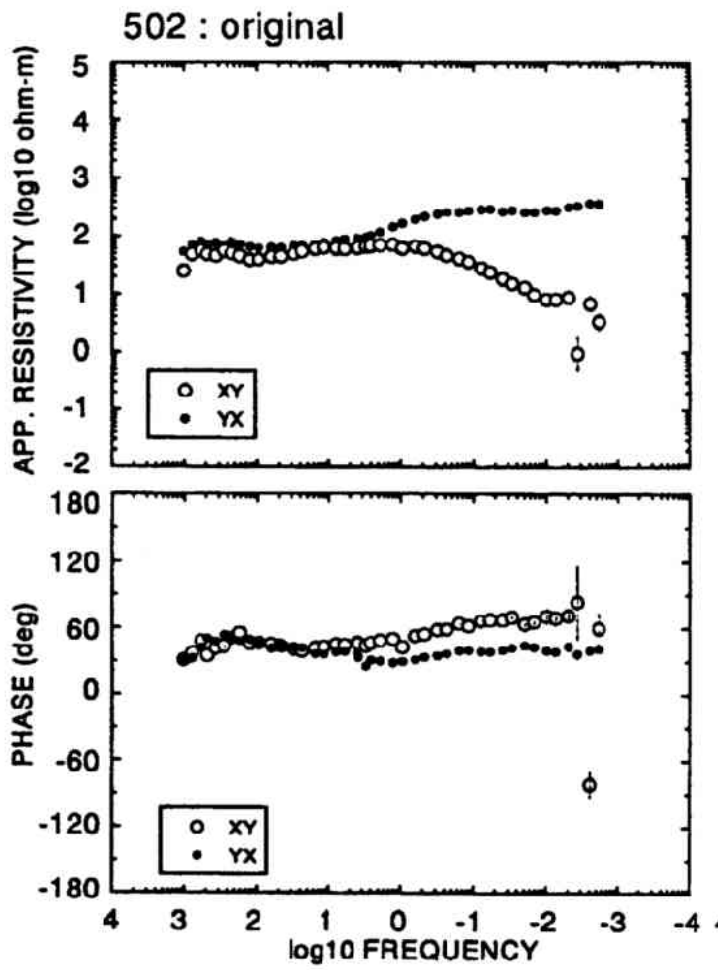

502 : after GBD
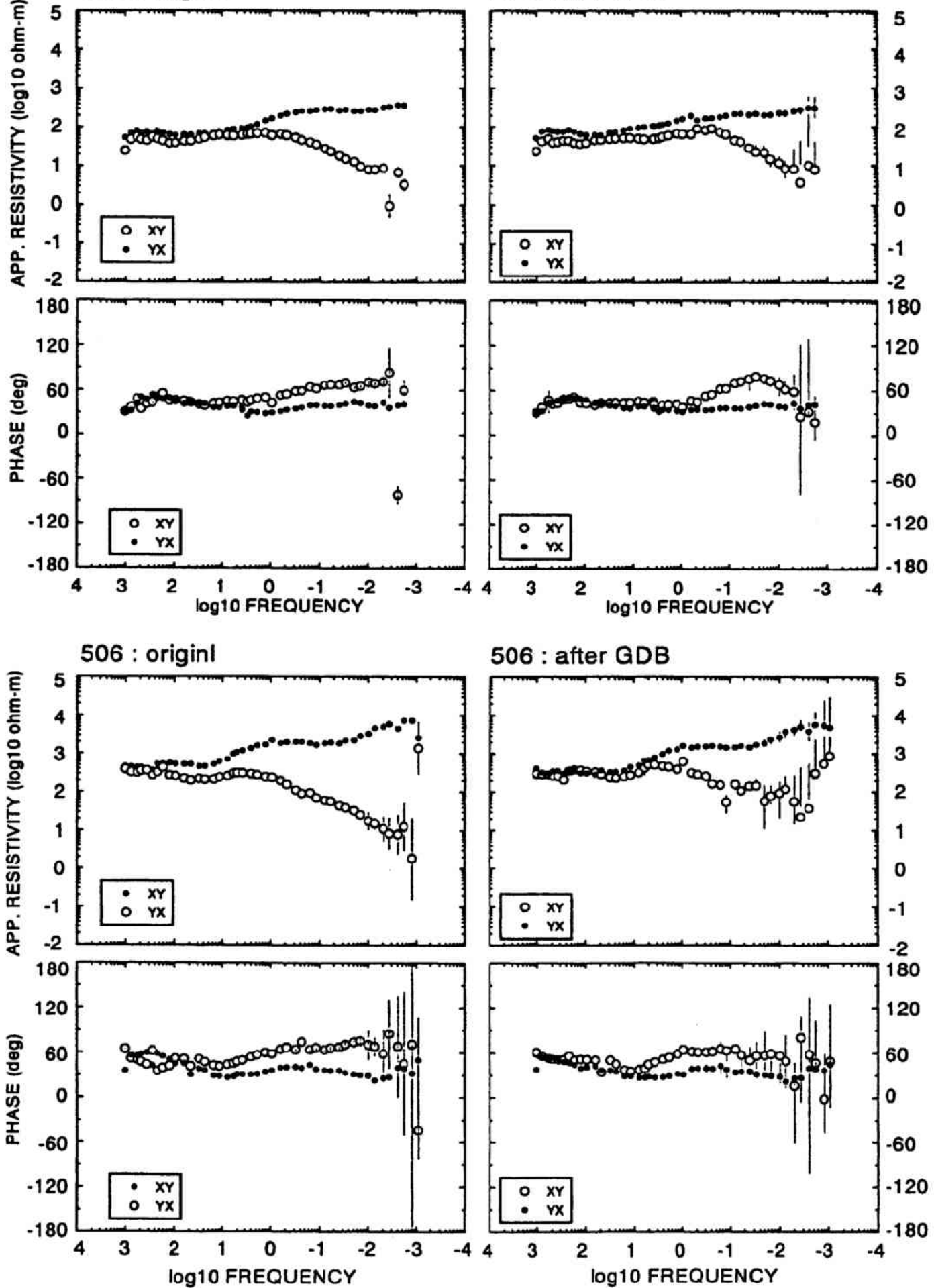

506 : after GDB

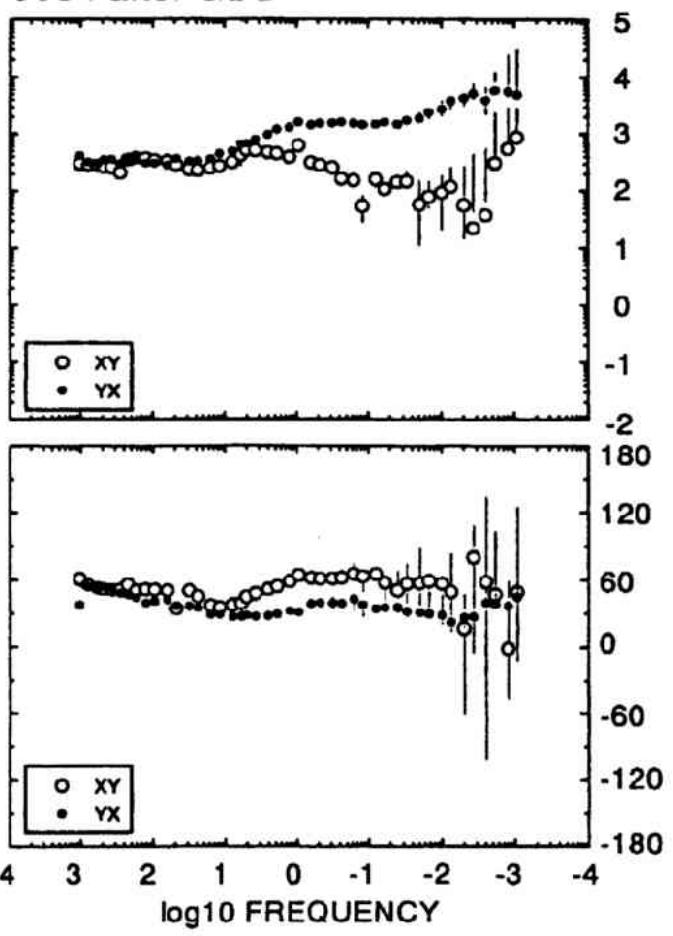

Fig. 8. Examples of the decomposed apparent resistivity and phase (right) and original ones (left) at Sites 502 and 506. 
observational environment. It is to be noted that the impedance strike direction determined by Swift's method does not provide a very smooth and systematic result $(\mathrm{F})$.

Figure 8 show the decomposed apparent resistivity and phase (right) and the original ones (left) at selected sites on Line C. Two-dimensional modeling using the undistorted impedances tensor deduced on the basis of the decomposition analysis is to be done in the future including adjustment of the site gain factor.

\section{Dimensionality of the Tohoku District}

The Groom and Bailey method assumed that local three-dimensional heterogeneities cause galvanic distortions over regionally two-dimensional structures. Therefore, it is important to investigate its applicability to the field data.

The impedance tensor skew was proposed as an effective parameter to quantify the three-dimension-

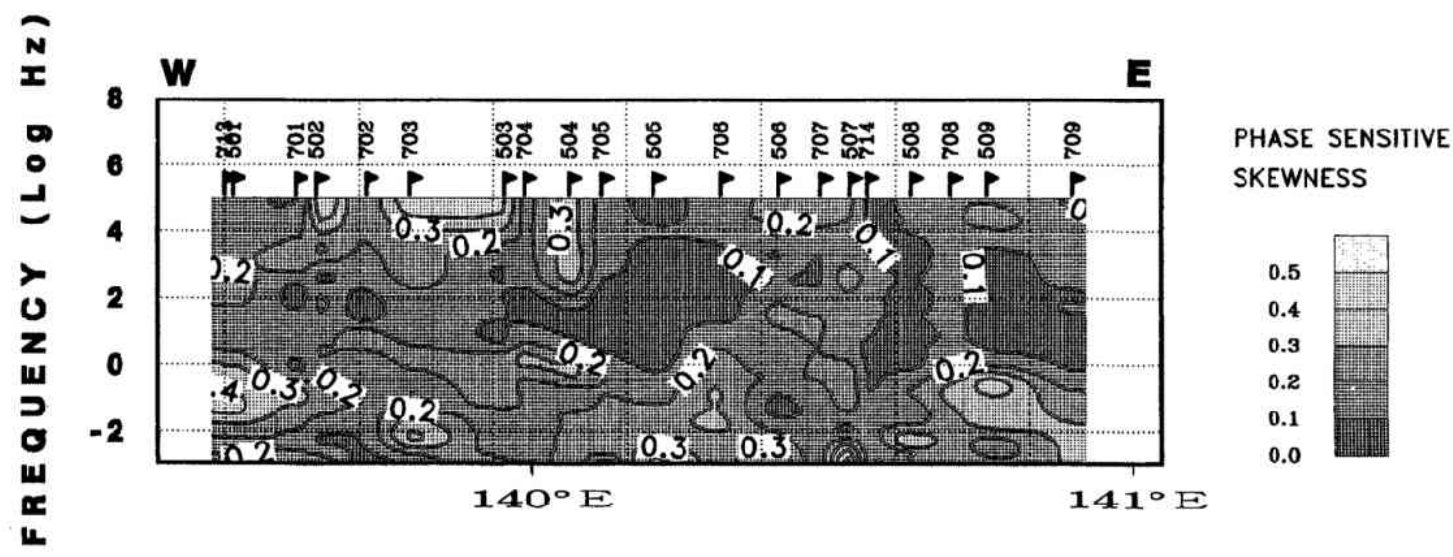

Fig. 9. The profile of the phase-sensitive skew along the Line C. The phase-sensitive skew is large at most of the sites in the frequency range below $0.1 \mathrm{~Hz}$.

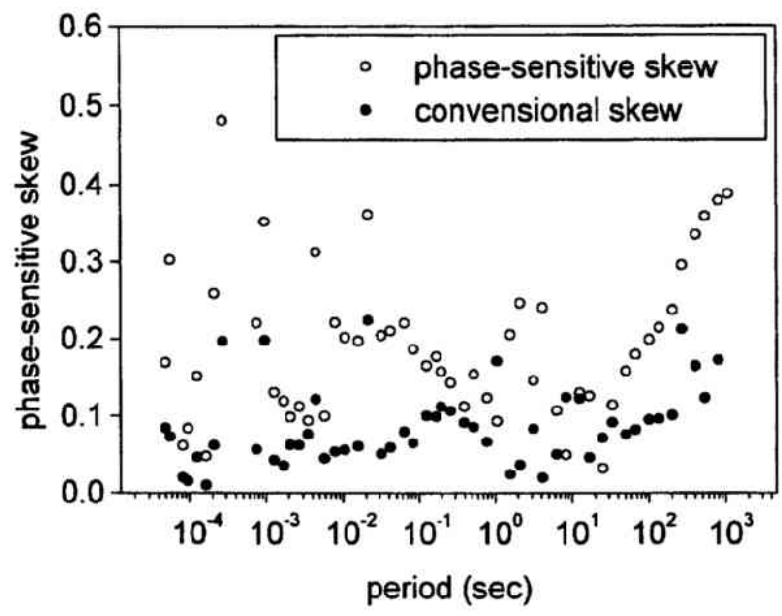

Fig. 10. Plots of the phase-sensitive skew (open circle symbols) and conventional skew (solid circle symbols) at Site 506. 
ality of the georesistivity distribution of the observation area (Swift, 1967). However, the conventional skew introduced by Swift (1967) can be sensitive to a local structure and so it may not be a proper indicator for regional three-dimensionality (Bahr, 1988). For example, in the presence of a local three-dimensional inhomogeneity overlaying a regional two-dimensional structure, the conventional skew may indicate a high value, even though the regional structure is two-dimensional. On the other hand, in the case of a regionally three-dimensional but locally two-dimensional profile, the conventional skew is small indicating a locally two-dimensional structure.

Instead of this conventional skew, a phase-sensitive skew (Bahr, 1988) is proposed, which is not affected by local structure and provides a proper indicator for regional three-dimensionality. Figure 9 is a plot of the phase-sensitive skew along Line C. At higher frequencies (nearly 10,000 Hz), the phasesensitive skew is small at the eastern part of the transect but large at the western part. In the frequency range $1,000 \mathrm{~Hz}$ to $0.1 \mathrm{~Hz}$, the phase-sensitive skew is rather small, especially at the eastern and central part of the line. Below $0.1 \mathrm{~Hz}$, the phase-sensitive skew is large at most of the sites, especially at both eastern and western ends of the line. The phase-sensitive skew indicates that the shallow depths are slightly threedimensional at the western part of Line $\mathrm{C}$ and the whole area exhibits three-dimensionality at depth.

On the other hand, the conventional skew is not as large as the phase sensitive skew. In Fig. 10, we show the conventional skew (solid circles) and phase sensitive skew (open circles) at Site 506. We can see that the conventional skew is sufficiently small, but that the phase-sensitive skew is rather large over the whole frequency range. This comparison lead us to think that the site is regionally three-dimensional and locally two-dimensional. The conventional skew is smaller than the phase-sensitive skew at most sites along Line $\mathrm{C}$ as observed at Site 506 suggesting that the local inhomogeneous structures are of nearly twodimensional features.

As mentioned in previous section, there were problems encountered when directly applying the decomposition technique to Site 509 at the eastern part of Line C. As shown in Fig. 9, the phase sensitive skew is large at Site 509 in the frequency range below $1 \mathrm{~Hz}$. Because of the indicated higher degree of regional three-dimensionality at Site 509, the Groom-Bailey decomposition technique could not be successfully applied. The large shear angle $\left(30^{\circ}\right)$ is also one of the causes. It is shown by Bahr (1991) that it is difficult to apply the Groom-Bailey decomposition method when the shear angle is close to 45 degrees.

Furthermore, the area is close to a large city, resulting in strong artificial noise around Site 509 . The presence of large cultural noise is considered as another reason for the difficulty in applying the GroomBailey decomposition because the contaminated datacould hardly be in the realm of the two-dimensionality as assumed by the GBD technique.

\section{Appropriateness of the Regional Strike}

The Groom-Bailey decomposition technique could not provide unique parameters when the structure is complex as was described above. Therefore the decomposition results might depend on the subjectivity of the interpreter. Thus it is important to take into consideration as much geological information as possible when working out the decomposition of data at a given site.

The magnetic transfer functions (tipper) can be useful in checking the results of the GBD method. While the local inhomogeneity causes galvanic distortions to the electric fields, the tipper is less affected by local distortion because the tipper depends only on the horizontal and vertical magnetic field data.

Figure 11 shows the tipper strike and the principle strike direction at Site 506 as determined by the conventional Swift parameterization. The figure also includes the regional strike and local current directions as determined by GBD. Note that the tipper strikes coincide well with the regional strike deduced by GBD. Therefore we can use the tipper to check the appropriateness of the regional strike as determined by the GBD technique.

In Fig. 11 the tipper strike is seen to undergo large variations and has a large confidence limit in the period range larger than $100 \mathrm{sec}$. We suspect that it is caused by large cultural noises around the site and is not indicative of true geological structure. In general, it is not easy to get high quality tipper data because 
of the weakness of vertical magnetic signal especially in civilized areas. We should take into account the data quality of the tipper when we use the tipper as a measure of the reliability of the decomposed parameters.

The induction vectors at a period of $16 \mathrm{sec}$ on the three transects are shown in Fig. 12 in comparison with the inferred regional strikes based on the Groom-Bailey decomposition method in the central part of

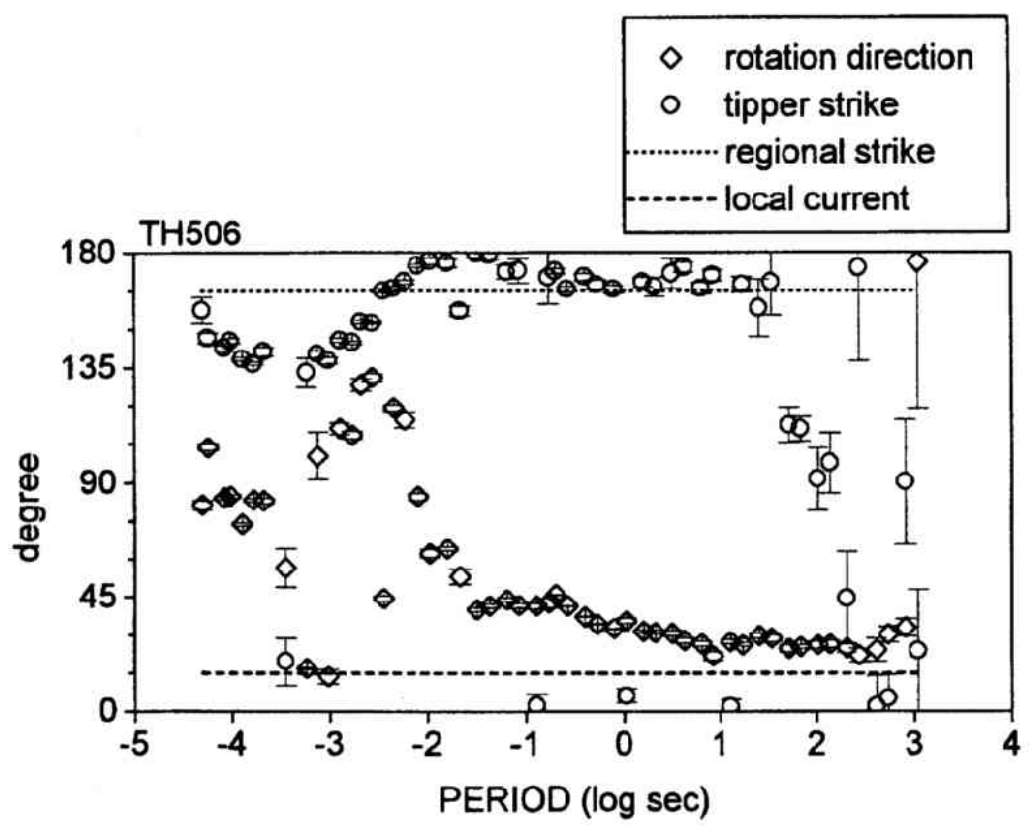

Fig. 11. The tipper strike, the principle strike direction as determined by a conventional Swift parameterization, the regional strike and the local current direction as determined by the Groom-Bailey decomposition method for Site 506.

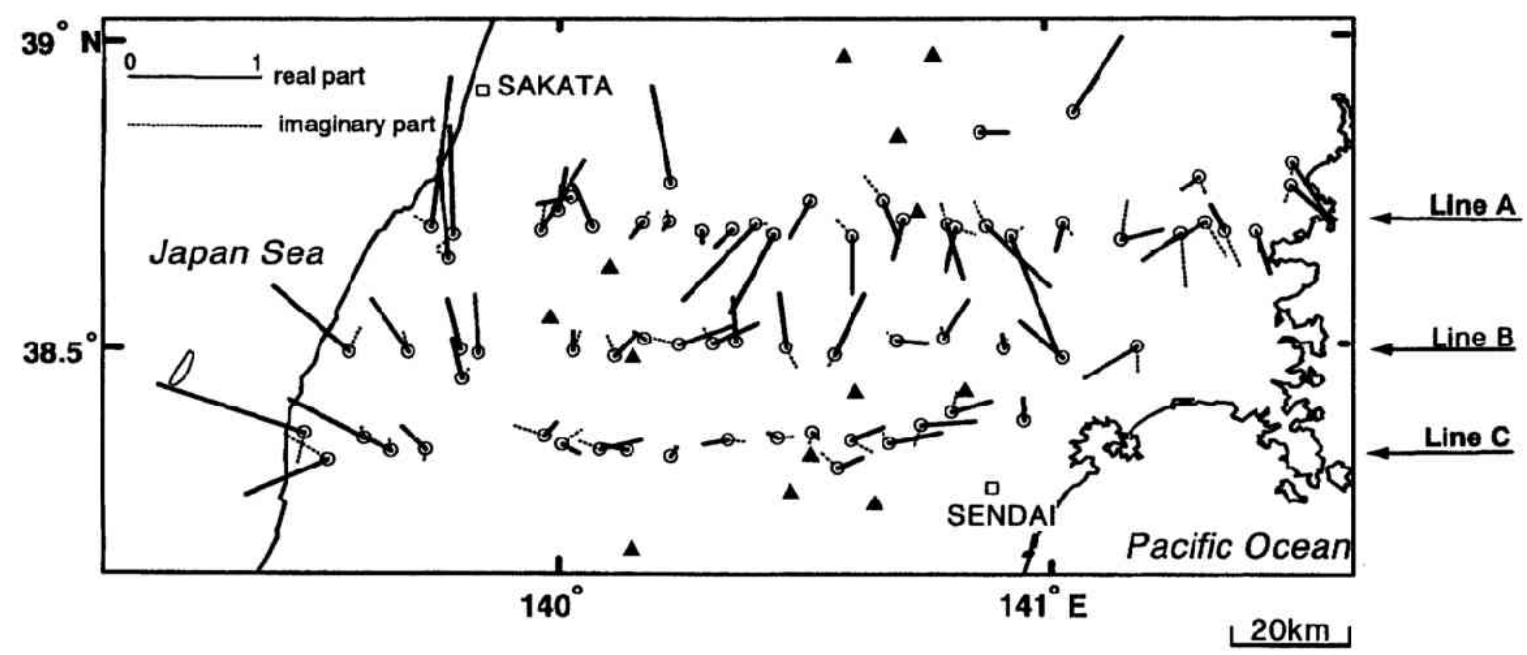

Fig. 12. Induction vectors at the period of 16 seconds at all sites on the three transects. Solid lines and dashed lines are real and imaginary parts of induction vectors, respectively. 
Tohoku. We selected this period because the effects of induced electrical currents due to the Straits of Tsugaru in the northern Tohoku district appeared at periods longer than this as reported by Ogawa (1987b). The tendency of the induction vectors pointing to the Japan Sea at sites on the western side can be explained by the coastal effect of the Japan Sea (Dosso, private communication) and the Tsugaru Strait (Ogawa, 1987b). We can see from Fig. 12 that it is difficult to infer the regional strike from the induction vectors due to the large scatter of the vectors' directions, in contrast to high degree of conformity of the regional strikes inferred from the decomposition procedure.

The structural direction inferred from the induction vectors on Line $\mathrm{C}$ is in agreement with those inferred from the decomposition procedure (Fig. 7) as well as the geology and tectonics (Figs. 1 and 2). The consistency could be explained by the small degree of three-dimensionality on Line $C$. The structural strike on Line $\mathrm{C}$ is thought to be basically north-south. It is noted that the impedance strike direction inferred from the conventional Swift's method is quite different from those based on the geology and tectonics.

The induction vectors on Lines A and B shown in Fig. 12 indicate the presence of conductive bodies in the middle part of the transects. On the other hand the regional strikes on Lines A and B inferred from the decomposition procedure are almost north to south (Fig. 7). We can think that the nearly north-south regional structure is superimposed by conductive bodies in the central regions of Lines $\mathrm{A}$ and $\mathrm{B}$. Thus we chose a north-south direction as the structural direction in 2D modeling in F.

\section{Concluding Remarks}

Wide-band MT data acquisition has been in progress in the central part of the Tohoku district in northeast Japan to help to reveal the geoelectrical structure of the active subduction zone. In this paper we have presented results of the Groom-Bailey decomposition method applied to all the data on the three transects in the Tohoku district as an important step towards evaluating three effects of galvanic distortion.

We could get reasonable results at the majority of the observational sites. However we could not simply apply the Groom-Bailey decomposition method for some sites because of either (1) some threedimensional structures in the deeper parts which were indicated by the phase-sensitive skew and/or (2) high degrees of local distortion indicated by shear angle and/or (3) abundant cultural noise. The induction vector is shown to provide effective information in estimating the regional strike on Line $\mathrm{C}$ but not on Line $\mathrm{A}$ and $\mathrm{B}$. The distortion parameters on some sites were large and had a dominant effect on the data.

Overall features of the decomposition parameters indicate that a north-northwest to south-southeast direction is the regional strike direction. The direction is consistent with the orientations of the major geological divisions in the area including major tectonic lines and the axis of the island arc.

The regional structure of the central part of Tohoku is suggested to be rather three dimensional at depth, as indicated by phase sensitive skew larger than 0.2 , strong scatter of both induction vectors and impedance strikes at periods longer than several tens of seconds. We need to pay attention to the situation especially when we interpret the deeper structure from lower crust to upper mantle on the basis of the two dimensional modeling result. Three dimensional modeling would be more appropriate.

The decomposition analysis can not directly provide knowledge about site gain, a factor used to determine static shifts (Groom and Bahr, 1992). The static shift can be solved in an 2-D inversion, but assumption must be made as to the distribution of the shift factors (Ogawa and Uchida, 1996). Evaluation of the site gain factors is underway at all the sites on the three transects in order to complete the correction of the observed impedance tensors induced by the surface galvanic distortion. The results will be reported in the near future.

We are grateful to many people and organizations who have contributed to this work. In particular, we would like to thank Drs. Hiroshi Takahashi, Shigetsugu Uehara, Gensuke Endo (late), Profs. Sachio Nabetani, Yoshimori Honkura for their continuous encouragement. We also thank Prof. K. Bahr and an anonymous referee for numerous comments and helpful suggestions on the manuscripts. 
This work was conducted under the funds of Science and Technology Agency Japan for the Promotion of Surveys and Research on Earth Science and Technology and Ocean Development.

\section{REFERENCES}

Bahr, K., Interpretation of the magnetotelluric impedance tensor: regional induction and local telluric distortion, J. Geophys., 62 , $119-127,1988$.

Bahr, K., Geological noise in magnetotelluric data: a classification of distortion types, Phys. Earth Planet. Inter., 66, 24-38, 1991.

Fujinawa, Y., T. Asch, N. Kawakami, N. Uyeshima, and Y. Honkura, Studies of the georesistivity structure in the central part of the northeastern Japan arc, J. Geomag. Geoelectr., 49, this issue, 1601-1617, 1997.

Geological Survey of Japan (ed.), Geological Map of Japan 1:1,000,000, 3rd Edition, CD-ROM Version, Digital Geoscience Map G-1, 1995.

Groom, R. W. and K. Bahr, Corrections for near-surface effects: decomposition of the magnetotelluric impedance tensor and scaling correction for regional resistivities, Surv. Geophys., 13, 341-380, 1992.

Groom, R. W. and R. C. Bailey, Decomposition of magnetotelluric impedance tensors in the presence of local three-dimensional galvanic distortions, J. Geophys. Res., 94, 1913-1925, 1989.

Groom, R. W. and R.C. Bailey, Analytical investigations of the effects of near-surface three-dimensional galvanic scatters on MT tensor decomposition, Geophysics, 56, 496-518, 1991.

Groom, R. W., R. D. Kurtz, A. G. Jones, and D. E. Boerner, A quantitative methodology to extract regional magnetotelluric impedances and determine the dimension of the conductivity structure, Geophys. J. Int., 115, 1095-1118, 1993.

Honkura, Y., Electrical conductivity anomalies beneath the Japan arc, J. Geomag. Geoelectr., 26, 147-171, 1974.

Kimura, T., I. Hayami, and S. Yoshida, Geology of Japan, 287 pp., Univ. Tokyo Press, Tokyo, 1991.

Ogawa, Y., Two-dimensional resistivity modeling based on regional magnetotelluric survey in the northern Tohoku district, $J$. Geomag. Geoelectr., 39, 349-366, 1987a.

Ogawa, Y., Preliminary interpretation on detailed magnetovariational profiling in the northern Tohoku district, J. Geomag. Geoelectr., 39, 559-569, 1987b.

Ogawa, Y., Deep crustal resistivity structure revealed by wideband magnetotellurics-Tohoku and Hokkaido region, Ph.D. Thesis, University of Tokyo, 320 pp., 1992.

Ogawa, Y. and T. Uchida, A two-dimensional magnetotelluric inversion assuming Gaussian static shift, Geophys. J. Int., 126, 69-76, 1996.

Ogawa, Y., T. Yukutake, and H. Utada, Two dimensional modeling of resistivity structure beneath the Tohoku district, northern Honshu of Japan, by a finite element method, J. Geomag. Geoelectr., 38, 45-79, 1986.

Oide, K., H. Nagawa, and S. Kanisawa (eds.), Regional Geology of Japan, Part 2 Tohoku, 338 pp., Kyoritsu Shuppan Co., Ltd, 1989 (in Japanese).

Swift, C., A magnetotelluric investigation of an electrical conductivity anomaly in the south western United States, Ph.D. Thesis, M.I.T., Cambridge, Mass., 1967.

Utada, H., A direct inversion method for two-dimensional modeling in the geomagnetic induction problem, Ph.D. Thesis, University of Tokyo, 409 pp., 1987. 